\title{
The Use of a Hand-held Smartphone Device for Non-invasive Thermal Observations of the Black Spiny-tailed Iguana (Ctenosaura similis) in Panama
}

\author{
Shem D. Unger ${ }^{1}$, Caleb Hickman², and Kevin Murray ${ }^{3}$ \\ ${ }^{1}$ Department of Biology, Wingate University, Wingate, North Carolina, 28174, USA (s.unger@wingate.edu) \\ ${ }^{2}$ Eastern Band of the Cherokee, Cherokee, North Carolina 28719, USA \\ ${ }^{3}$ Western Ecosystems Technology, Inc, Bloomington, Indiana 47404, USA
}

$\mathrm{T}$ he Black Spiny-tailed Iguana (Ctenosaura similis) is a large iguanid lizard found across Neotropical lowland habitats from Mexico south through much of Costa Rica and Panama, where it occurs in a variety of human altered and natural habitats (Savage 2002; Powell 2004). Throughout the range, $C$. similis is frequently observed basking in urban areas, including garden patios and greenways (Fitch et al. 1982; Gonzalez-Garcia et al. 2009). Although C. similis is quite cosmopolitan (Stephen et al. 2011), many gaps remain in our understanding of their basic natural history, including thermal ecology (e.g., basking site preferences). This lack of knowledge may be partially attributable to the difficulty of collecting data.

Traditionally, internal body temperatures are collected by capturing lizards and invasively probing the cloaca with a thermometer. Lizards are very good at evading capture by dropping from tree limbs into water or vegetation. In addition, invasive cloacal probing could alter behaviors, which could in turn bias a study about basking ecology and evolution. However, a new technology allows a researcher to obtain data efficiently without handling animals. Thermal imaging involves remotely characterizing the surface temperature of objects using camera sensors sensitive to infrared wavelengths emitted by objects. This technology generates a color-scaled image made up of pixels representing a range of temperatures (e.g., McCafferty 2013; Allen and Powell 2014; Hart et al. 2015). This technology has been recently applied to both endothermic and ectothermic vertebrates, including observations on the ability of reptiles to thermoregulate (Tattersall and Cadena 2010). New emerging, affordable smartphone thermal imaging technologies, include the FLIRONE infrared camera for iOS and Android, are non-invasive, minimize disturbance of animals, and allow for observation of thermal site selection by lizards. Herein, we describe observations of
C. similis in Panama using thermal imaging by a FLIRONE camera to evaluate a frequently used basking site.

On 7-10 January 2018, we repeatedly observed a single C. similis while it was basking on top of the same downed tree limb in full sun (approximately $0.2 \times 1.9$ m exposed length). This site was in a dry secondary coastal forest at $-15 \mathrm{~m}$ elevation within the Chiriqui Province of Panama $\left(8.206785^{\circ} \mathrm{N}\right.$, $-82.189625^{\circ} \mathrm{W}$; WGS84). With elevated temperatures during peak basking times (between $-1000-1500 \mathrm{~h}$ ), a single observer documented temperatures on the lizard's dorsal side, basking site, and surroundings. To collect thermal data, we used the FLIRONE smartphone attachment with applications for an iPod (FLIR Systems, Inc.; www.flir.com) periodically using the spot meter feature, which displays a temperature average within the image (Fig. 1). This camera consists of a 17 -micron thermal sensor, $80 \times 60$ thermal resolution, $1440 \times 1080$ thermal resolution, $50 \pm 1{ }^{\circ} \mathrm{C}$ horizontal field of view, and $38 \pm 1{ }^{\circ} \mathrm{C}$ vertical field of view, and a dynamic range of $-20-120^{\circ} \mathrm{C}$ (www.flir.com). We photographed and generated thermal images of dorsal surface temperatures of the iguana using the infrared camera from a distance of 4.5 $\mathrm{m}$. From eight observations, we determined that the lizard's mean dorsal surface temperature was $33.03 \pm 0.37^{\circ} \mathrm{C}( \pm$ one $\mathrm{SD})$, the mean temperature of the basking limb was $35.80 \pm$ $2.96{ }^{\circ} \mathrm{C}$, and the mean ambient surrounding temperature in the shade was $28.92 \pm 1.67^{\circ} \mathrm{C}$.

These observations illustrate the potential for using a compact and non-invasive method for studying the thermal ecology of basking lizards. Although thermal ecology has been studied more extensively in endotherms, Tattersall et al. (2016) observed that tegu lizards were able to maintain body temperatures well above ambient. Stapley and Keogh (2004) found the dorsal surface between the shoulders of Southern Water Skinks (Eulamprus heatwolei) to be consistent with 
internal temperature readings measured by anal probe, highlighting the potential for further studies of thermal ecology in other lizards using thermal imaging cameras. These methods

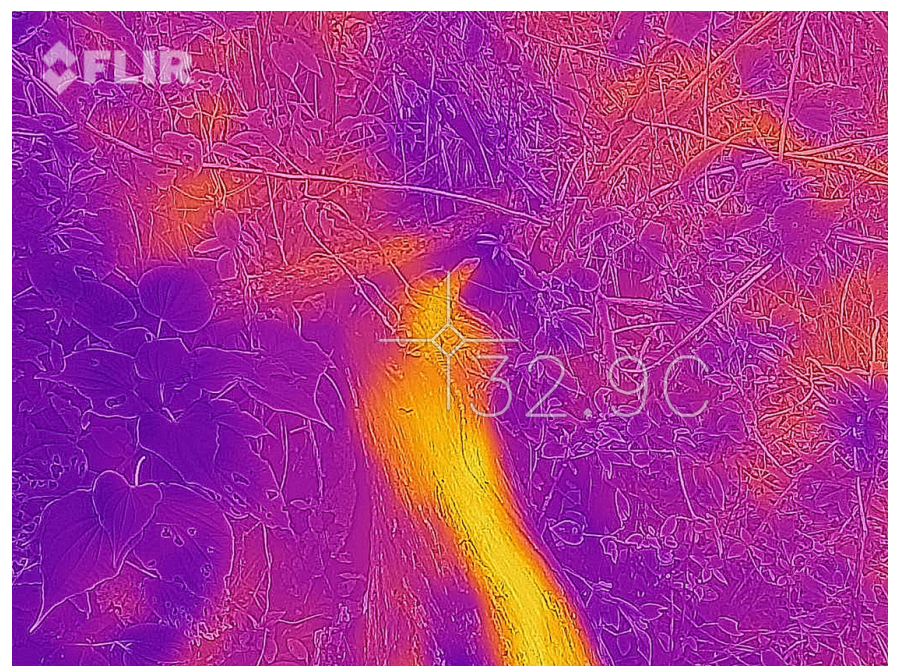

provide researchers and the general public with an accessible way to obtain data from animals that can easily escape if pursued, and to do so without altering important behaviors that could bias the very thermal condition we want to explore. Additional applications of this non-invasive, smartphoneenabled thermal imaging camera include characterization of surface temperatures of other basking reptiles (especially elusive species), physiological studies, behavioral ecology, and habitat selection studies.

\section{Acknowledgements}

We thank Wingate University Biology Department and WINGS Travel Grant for funding and La Fundacion Kucikas for logistical support.

\section{Literature Cited}

Allen, K.E. and R. Powell. 2014. Thermal biology and microhabitat use in Puerto Rican Eyespot Geckos (Sphaerodactylus macrolepis macrolepis). Herpetological Conservation and Biology 9: 590-600.
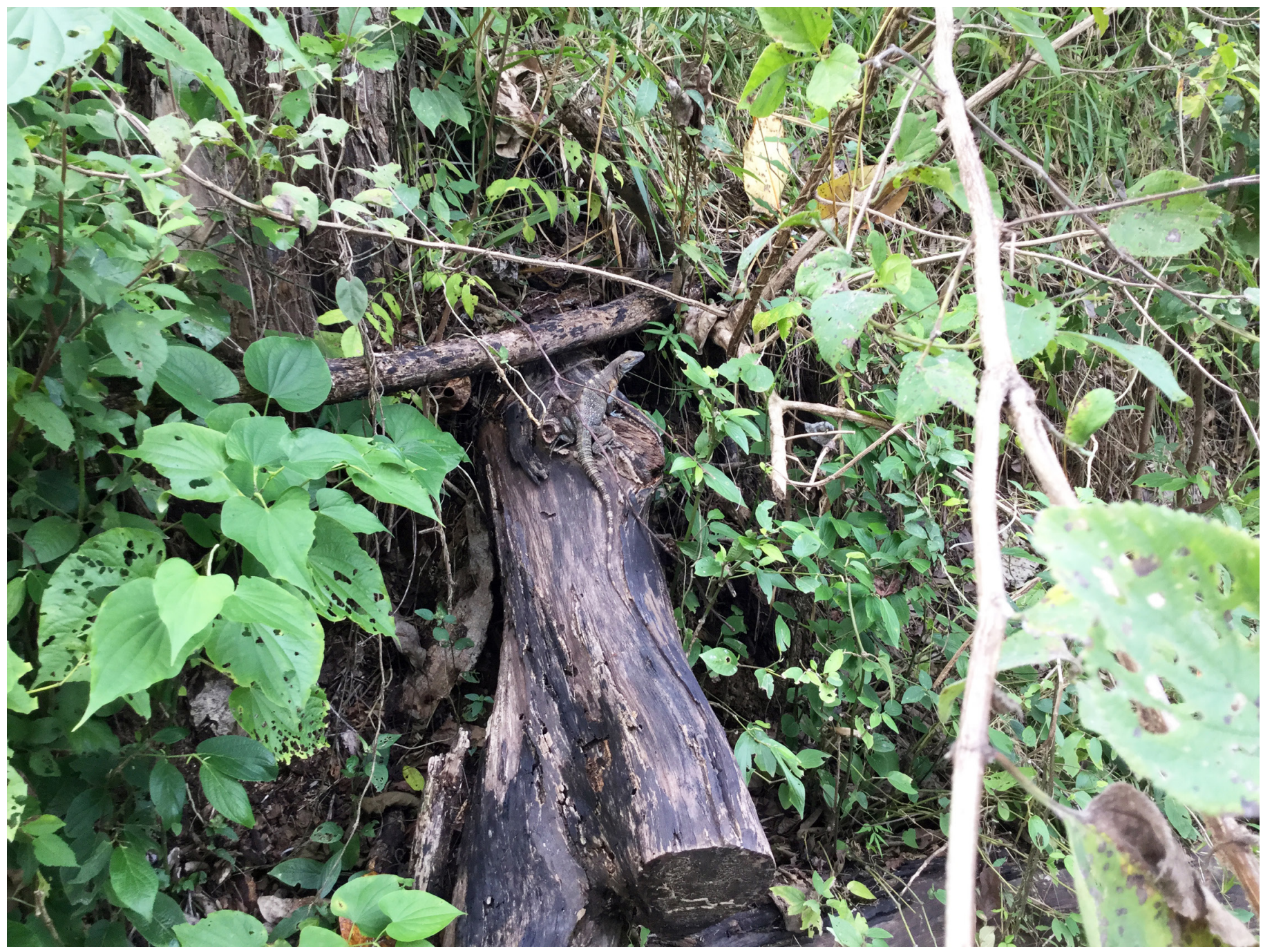

Fig. 1. Infrared thermal imaging characterization of basking site, lizard body surface, and ambient temperature for a Black Spiny-tailed Iguana (Ctenosaura similis) taken with FLIRONE illustrating yellow-orange signatures of elevated temperature, with lower surrounding temperatures illustrated by magentaviolet (top), and a standard non-thermal image (bottom) during an observation period. Photographs by the senior author. 
Fitch, H.S., R.W. Henderson, and D.M. Hillis. 1982. Exploitation of Iguanas in Central America, pp. 397-417. In: G. Burghardt and A.S. Rand (eds.), Iguanas of the World: Their Behavior, Ecology, and Conservation. Noyles Publications, Park Ridge, New Jersey.

Gonzalez-Garcia, A., J. Belliure, A. Gomez-Sal, and P. Davila. 2009. The role of urban greenspaces in fauna conservation: The case of the iguana Ctenosara similis in the 'patios' of Leon city, Nicaragua. Biological Conservation 18: 1909-1920.

Hart, A.G., R.N. Rolfe, S. Dandy, H. Stubbs, D. MacTavish, L. MacTavish, and A. E. Goodenough. 2015. Can handheld thermal imaging technology improve detection of poachers in African bushveldt? PLOS ONE 10(6): 1-13.

McCafferty, D.J. 2013. Applications of thermal imaging in avian science. Ibis 155: $4-15$.

Powell, R. 2004. Black Iguanas (Ctenosaura similis) in Guanacaste, Costa Rica. Iguana 11: 17-19.
Savage, J.M. 2002. The Amphibians and Reptiles of Costa Rica: A Herpetofauna between Two Continents, between Two Seas. University of Chicago Press, Chicago, Illinois.

Stapley, J. and J.S. Keogh. 2004. Exploration and antipredator behaviors differ between territorial and nonterritorial male lizards. Animal Behavior 68: 841-846.

Stephen, C., S. Pasachnik, A. Reuter, P. Mosig, L. Ruyle, and L. Fitzgerald. 2011. Survey of status, trade, and exploitation of Central American iguanas. Report, Department of Interior, United States Fish and Wildlife Service, Washington, D.C.

Tattersall, G.J. and V. Cadena. 2010. Insights into animal temperature adaptations revealed through thermal imaging. The Imaging Science Journal 58: 261-268.

Tattersall, G.J., C.A.C. Leite, C.E. Sanders, V. Cadena, D.V. Andrade, A.S. Abe, and W.K. Milsom. 2016. Seasonal reproductive endothermy in tegu lizards. Science Advances 2: 1-7. 